\title{
Genetic analysis of fleece and post-weaning body weight traits in Makuie sheep
}

\author{
S. Jafari ${ }^{1,2}$ and A. Hashemi ${ }^{1}$ \\ ${ }^{1}$ Department of Animal Science, Faculty of Agriculture, Urmia University, \\ Urmia, Iran \\ ${ }^{2}$ West Azerbaijan Jihad-Agriculture Organization, \\ Makuie Sheep Breeding Station, Maku City, Iran \\ Corresponding author: S. Jafari \\ E-mail: Jafarishoja@yahoo.com
}

Genet. Mol. Res. 13 (1): 1079-1087 (2014)

Received January 18, 2013

Accepted July 10, 2013

Published February 20, 2014

DOI http://dx.doi.org/10.4238/2014.February.20.9

\begin{abstract}
Estimation of genetic parameters is the most important component of an organized selection program. With respect to economic traits, such as wool and mutton traits, production costs can be reduced through a suitable selection program focused on genetic improvement. This study aimed to evaluate genetic parameters of fleece and post-weaning growth traits in sheep. Greasy fleece weight at $6,16,28,40$, and 52 months of age (GFW1, GFW2, GFW3, GFW4, and GFW5) represented characteristics of wool quantity. Staple length at shoulder, side, and rump (SL1, SL2, and SL3), fiber diameter, and percentage of true wool (TW\%) were used as characteristics of wool quality. Live body weight at 6, 9, and 12 months of age (BW6, BW9, and BW12) reflected post-weaning growth characteristics. These data were collected over 23 years, from 1989 to 2012, at the Makuie Sheep Breeding and Raising Station (MSBS). Estimations were calculated using the derivative-free restricted maximum likelihood (DFREML) model. Direct heritability estimates, based on single-trait analyses, ranged from 0.10 (GFW1) to 0.80 (TW\%). Additive genetic correlations among the traits ranged from highly negative $(-0.46)$ to highly positive
\end{abstract}


(0.99). The log likelihood ratio test (LRT) was used for selection of the most appropriate model. Based on the LRT, direct additive genetic and maternal permanent environmental effects were considered as the main sources of variation in the studied traits.

Key words: Fleece traits; Post-weaning traits; Genetic parameters; Correlations; Makuie sheep breed

\section{INTRODUCTION}

The Makuie sheep breed is a native breed of the Azerbaijan Province (Iran) and can be found in Turkey, where it is known as White Karaman. Its total population in Iran is estimated to be 2.7 million (Abbasi and Ghafouri-Kesbi, 2011). Makuie is a medium-sized (ewes $=45-48 \mathrm{~kg}$, rams $=51-53 \mathrm{~kg}$ ) and fat-tailed sheep breed that is adapted to cold and highland environments (Safari, 1986). Its body is most commonly white in color, and it has black rings around the eyes, nose, and knees (Saadatnoori and Siahmansoor, 1986).

The Makuie Sheep Breeding and Raising Station (MSBS) rearing system consists mostly of extensive-migration on natural pastures in spring and summer (April to September) and semi-intensive in-station rearing with barn feeding during autumn and winter (October to March). Alfalfa, barley, corn silage, concentrates, and grass are used to feed the animal during the semi-intensive rearing period. The breeding season begins in late summer and lasts until early autumn. Estrus synchronization is carried out in the flock with a progesterone-releasing intra-vaginal device (CIDR). Ewes are bred either via artificial insemination in the first cycle of estrus or with controlled rams in the second or third cycle of estrus. Two programs are applied to increase litter size: flushing (feeding ewes with a high-energy diet 2-3 weeks before breeding season) and equine chorion gonadotrophin injection upon CIDR removal. Ewes are kept in the flock for a maximum of 7 parities and rams remain in the flock for 5 breeding season. Lambing occurs once a year, and lambing season begins in the last month of winter (late January). Lambs receive creep feeding at 2 weeks of age (Jafari et al., 2012). Shearing of adult animals and lambs is performed in late May and early July, respectively. One week before shearing, animals are submersed in an anti-parasite bath.

In sheep breed classification based on wool characteristics, Iranian sheep breeds are classified as carpet or coarse wool breeds. The fiber diameter of these breeds ranges from 35 to 50 microns. The white body color, and subsequently the white-colored wool, is an advantage of Iranian sheep breeds because white wool can be dyed more easily than colored wool and is therefore of higher economic value. Fibers from adult sheep are categorized into four main types: hair, heterotype, wool, and kemp (Lang, 1950; Ryder and Stephenson, 1968). Heterotype fibers are the main part of the whole fleece produced by Iranian sheep breeds including Lori, Kermani, Baluchi, Moghani, and Makuie, comprising 65-70\% of the wool staple.

Heterotype fibers are characteristic of sheep that are primarily reared on a migratory system in which feed supplementation varies from season to season (Saadatnoori and Siahmansoor, 1986).

Although the main purpose of Makuie sheep flock holders is mutton production and wool is considered as a by-product, wool nonetheless plays an important role in the welfare and economy of the country. Iran's famous carpet industry and other wool-related handicrafts are dependent on white and coarse wool sheep breeds such as Makuie (Saadatnoori and Siahmansoor, 1986). 
Effective genetic evaluations for the development of suitable breeding programs to select for economically valuable traits, such as wool and growth, require detailed knowledge of the genetic parameters underlying these traits (Safari et al., 2005). Although the Makuie population has been under selection for at least 25 years, to our knowledge, no study has yet estimated genetic parameters for fleece traits in this sheep breed. Therefore, the objectives of the present study were to estimate the genetic parameters of fleece and post-weaning traits, and to reveal any associations between traits using genetic correlation analysis.

\section{MATERIAL AND METHODS}

\section{Data structure}

Fleece and post-weaning data of 3674 lambs from 163 sires and 1558 dams recorded over 23 years, from 1989 to 2012, at the MSBS were used in the present study. Traits related to wool quality characteristics were greasy fleece weight at $6,16,28,40$, and 52 months of age (GFW1, GFW2, GFW3, GFW4 and GFW5). Traits representing the quality characteristic of wool were staple length at shoulder, side, and rump (SL1, SL2, and SL3), fiber diameter (FD), and the percentage of true wool (TW\%). Post-weaning growth traits were considered as live body weight at 6, 9, and 12 months of age (BW6, BW9 and BW12).

Basic statistical analysis of the data was conducted using the SAS software (2002). Probable errors in the pedigree file were detected using the Pedigree software (2000).

\section{Models for data analysis}

Variance and covariance components were estimated based on an animal model with a restricted maximum likelihood (REML) approach using a derivate-free (DF) algorithm (Meyer, 1989). The year of birth (for post-weaning traits), year of shearing (for fleece traits), sex, birth type, and age of dam had 23,23, 2, 3, and 6 levels, respectively, and were considered as fixed effects. Six different univariate models were fit for each trait. They differed with respect to random effects and interactions. Maternal genetic or permanent environmental effects were taken into account by including them in appropriate models, as described by Meyer (1992). The linear forms of the six models were:

$$
\begin{aligned}
& \text { Model I: } \mathrm{Y}_{\mathrm{ijk} k m n}=\mu+\mathrm{YR}_{\mathrm{i}}+\mathrm{SX}_{\mathrm{j}}+\mathrm{BT}_{\mathrm{k}}+\mathrm{AD}_{1}+\mathrm{AN}_{\mathrm{m}}+\mathrm{E}_{\mathrm{ijk} k m n} \\
& \text { Model II: } \mathrm{Y}_{\mathrm{ijklm} n}=\mu+\mathrm{YR}_{\mathrm{i}}+\mathrm{SX}_{\mathrm{j}}+\mathrm{BT}_{\mathrm{k}}+\mathrm{AD}_{1}+\mathrm{AN}_{\mathrm{m}}+\mathrm{PE}_{\mathrm{n}}+\mathrm{E}_{\mathrm{ijklmn}}
\end{aligned}
$$

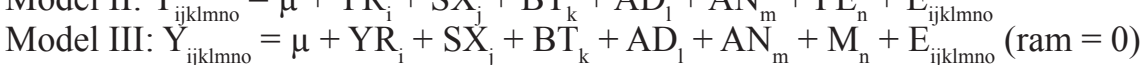

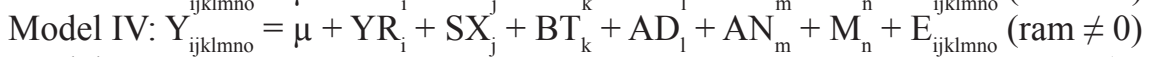

$$
\begin{aligned}
& \text { Model V: } \mathrm{Y}_{\text {ijklmnop }}=\mu+\mathrm{YR}_{\mathrm{i}}+\mathrm{SX}_{\mathrm{i}}+\mathrm{BT}_{\mathrm{k}}+\mathrm{AD}_{1}+\mathrm{AN}_{\mathrm{m}}+\mathrm{M}_{\mathrm{n}}+\mathrm{PE}_{\mathrm{o}}+\mathrm{E}_{\mathrm{ijklmnop}}(\mathrm{ram}=0) \\
& \text { Model VI: } \mathrm{Y}_{\mathrm{ij} k \mathrm{k} \text { mno }} \mathrm{p}=\mu+\mathrm{YR}_{\mathrm{i}}+\mathrm{SX}_{\mathrm{j}}+\mathrm{BT}_{\mathrm{k}}+\mathrm{AD}_{1}+\mathrm{AN}_{\mathrm{m}}+\mathrm{M}_{\mathrm{n}}+\mathrm{PE}_{\mathrm{o}}+\mathrm{E}_{\mathrm{ijk} / \mathrm{knnop}}(\mathrm{ram} \neq 0)
\end{aligned}
$$

Where $Y_{i j k} \ldots$ represents each underlying trait value belonging to its appropriate group; $\mu$ is the overall mean of the population; $Y R_{i}$ is the fixed effect of year I; $S X_{j}$ is the fixed effect of sex $\mathrm{j} ; B T_{k}$ is the fixed effect of birth type k; $A D_{l}$ is the fixed effect of dam age 1; $A N_{m}$ is the individual additive genetic effect of animal $\mathrm{m} ; P E_{n}$ is the random effect of the permanent maternal environment over $\mathrm{n}$ levels ( $\mathrm{n}=$ number of maternal levels for each trait); $M_{n}$ is the maternal genetic effect; $E_{i j k} \ldots$ is the residual random effect of observation $\mathrm{ijk} \ldots$ 
Depending on the fitted model, the direct additive genetic variance $\left(\sigma^{2}\right)$, maternal genetic variance $\left(\sigma_{\mathrm{m}}^{2}\right)$, permanent environmental variance $\left(\sigma_{\mathrm{pe}}^{2}\right)$, and residual variance $\left(\sigma_{\mathrm{e}}^{2}\right)$ were considered as the main sources of phenotypic variance $\left(\sigma_{\mathrm{p}}^{2}\right)$. The direct heritability $\left(\mathrm{h}_{\mathrm{a}}^{2}\right)$, maternal heritability $\left(\mathrm{h}_{\mathrm{m}}{ }^{2}\right)$, and the heritability due to the permanent environment $\left(\mathrm{C}^{2}\right)$ were estimated by dividing $\sigma_{\mathrm{a}}^{2}, \sigma_{\mathrm{m}}^{2}$, and $\sigma_{\mathrm{pe}}^{2}$ by $\sigma_{\mathrm{p}}^{2}$, respectively. The genetic covariance between direct and maternal genetic effects $\left(\sigma^{22}{ }^{\text {pe }}\right)$, and consequently the correlation between these effects $\left(\mathrm{r}_{\mathrm{am}}\right)$ were considered in Models IV and VI.

\section{RESULTS AND DISCUSSION}

\section{Descriptive statistics}

Number of data entries, trait means, standard deviations, coefficients of variation (CV), and the range of trait values are presented in Table 1. Traits recorded from older animals had relatively less data. In the present study, the data for GFW1 and GFW5 contained 3659 and 795 entries, respectively. This decline was due to the regular culling of the flock. As shown in Table 1, the mean CV value for post-weaning traits was determined to be 17.3. Whereas, this value was estimated to be 26.83 for fleece-related traits. Similar results were reported by other authors (Snyman et al., 1995, 1996). The relatively low CV of post-weaning traits indicated higher uniformity of these traits. The low CV for body weight traits, reflecting the relatively high uniformity among the population, may be due to small differences among animals, minor changes of these traits by similar environmental conditions, and other unknown factors.

Table 1. Descriptive statistics of the fleece and post-weaning live body weight traits in Makuie sheep.

\begin{tabular}{|c|c|c|c|c|c|}
\hline Trait & $\mathrm{N}$ & Mean & SD & $\mathrm{CV}$ & Range \\
\hline GFW1 (kg) & 3659 & 0.45 & 0.13 & 28.31 & $0.10-1.60$ \\
\hline GFW2 (kg) & 2076 & 1.20 & 0.38 & 31.29 & $0.10-3.25$ \\
\hline GFW3 (kg) & 957 & 1.67 & 0.52 & 30.97 & $0.50-5.00$ \\
\hline GFW4 (kg) & 986 & 1.68 & 0.51 & 30.32 & $0.50-3.80$ \\
\hline GFW5 (kg) & 795 & 1.67 & 0.50 & 30.13 & $0.30-3.70$ \\
\hline BW6 (kg) & 3674 & 27.44 & 4.98 & 18.15 & $11.00-51.00$ \\
\hline BW9 (kg) & 2995 & 28.60 & 4.64 & 16.22 & $16.00-46.50$ \\
\hline BW12 (kg) & 2168 & 33.30 & 5.84 & 17.53 & $16.90-59.00$ \\
\hline $\operatorname{FD}(\mu)^{*}$ & 193 & 32.24 & 5.23 & 16.23 & $9.17-48.12$ \\
\hline $\mathrm{SL} 1(\mathrm{~cm})$ & 200 & 15.16 & 3.74 & 24.66 & $7.00-29.33$ \\
\hline $\mathrm{SL} 2(\mathrm{~cm})$ & 200 & 14.13 & 3.59 & 25.39 & $7.83-25.63$ \\
\hline $\mathrm{SL} 3(\mathrm{~cm})$ & 200 & 14.41 & 3.49 & 24.20 & $8.00-28.50$ \\
\hline$\% \mathrm{TW}^{*}$ & 193 & 97.23 & 4.60 & 15.21 & $94.00-100$ \\
\hline$\% \mathrm{H}^{*}$ & 193 & 2.07 & 2.64 & 27.35 & $0.00-16.80$ \\
\hline$\% \mathrm{~K}^{*}$ & 193 & 0.67 & 2.40 & 28.19 & $0.00-21.00$ \\
\hline
\end{tabular}

*This traits are related to middle area of body; $\mathrm{N}=$ No. of records; $\mathrm{SD}=$ standard deviation; GFW1 = greasy fleece weight at 6 months of age; GFW2 = greasy fleece weight at 16 months of age; GFW3 = greasy fleece weight at 28 months of age; GFW4 = greasy fleece weight at 40 months of age; GFW5 = greasy fleece weight at 52 months of age; BW6 = body weight at 6 months of age; BW9 = body weight at 9 months of age; BW12 = body weight at yearling age; FD = fiber diameter; SL1 = staple length (shoulder); SL2 = staple length (side); SL3 = staple length (rump); $\% \mathrm{TW}=$ percentage of true wool, $\% \mathrm{H}$; percentage of hair; $\% \mathrm{~K}=$ percentage of kemp.

Based on data obtained from another Iranian sheep breed (Taherpour et al., 2012), the wide variation of fleece and post-weaning traits in Makuie sheep suggests potential for improvement of these economically important traits. 


\section{Fixed effects}

The data structure resulting from incorporation of fixed effects of fleece and postweaning traits are presented in Table 2 . The environmental factors considered showed significant effects on the Makuie sheep traits analyzed. The sex of the animal was found to have nonsignificant to significant $(\mathrm{P}<0.001)$ effects on different traits. Males were $0.02,0.20,0.42$, $0.85,0.84,2.80,3.25$, and $8.35 \mathrm{~kg}$ heavier than females for GFW1, GFW2, GFW3, GFW4, GFW5, BW6, BW9, and BW12, respectively. For SL1 and SL2, females were longer than males by 2.00 and $1.70 \mathrm{~cm}$, respectively. The effect of sex on other traits was non-significant. Significant effects of sex on economically relevant traits have also been reported by other researchers (Snyman et al., 1995; Mohammadi et al., 2010; Taherpour et al., 2012).

Table 2. Analysis of variance for fleece and post weaning live body weight traits in Makuie sheep breed.

\begin{tabular}{|c|c|c|c|c|c|}
\hline \multirow[t]{2}{*}{ Trait } & \multicolumn{5}{|c|}{ Fixed effects } \\
\hline & SY & BY & Sex & BT & $\mathrm{AD}$ \\
\hline GFW1 & NS & - & $* * *$ & $* * *$ & $* *$ \\
\hline GFW2 & $* * *$ & - & $* * *$ & NS & NS \\
\hline GFW3 & NS & - & $* * *$ & NS & NS \\
\hline GFW4 & NS & - & $* * *$ & NS & *** \\
\hline GFW5 & $* * *$ & - & $* * *$ & $* * *$ & NS \\
\hline BW6 & - & $* * *$ & $* * *$ & $* * *$ & $* *$ \\
\hline BW9 & - & $* * *$ & $* * *$ & $* * *$ & $*$ \\
\hline BW12 & - & NS & $* * *$ & $* * *$ & $* *$ \\
\hline FD & - & NS & NS & NS & NS \\
\hline SL1 & - & NS & $* * *$ & $*$ & NS \\
\hline SL2 & - & $*$ & $* * *$ & $*$ & NS \\
\hline SL3 & - & NS & NS & NS & NS \\
\hline$\% \mathrm{TW}$ & - & NS & NS & NS & NS \\
\hline$\% \mathrm{H}$ & - & *** & NS & NS & NS \\
\hline$\% \mathrm{~K}$ & - & NS & NS & NS & NS \\
\hline
\end{tabular}

GFW1 = greasy fleece weight at 6 months age; GFW2 = greasy fleece weight at 16 months age; GFW3 = greasy fleece weight at 28 months of age; GFW4 = greasy fleece weight at 40 months of age; GFW5 = greasy fleece weight at 52 months of age; BW6 = body weight at 6 months of age; BW9 = body weight at 9 months of age; BW12= body weight at yearling age; FD = fiber diameter; SL1 = staple length (shoulder); SL2 = staple length (side); SL3 = staple length (rump); \% TW = percentage of true wool; $\% \mathrm{H}=$ percentage of hair; $\% \mathrm{~K}=$ percentage of kemp; $\mathrm{SY}$ $=$ shearing year; $\mathrm{BY}=$ birth year; $\mathrm{BT}=$ birth type $\mathrm{AD}=$ age of dam; $\mathrm{NS}=$ non- significant; *significant at 0.05 probability level; **significant at 0.01 probability level; ***significant at 0.001 probability level. $(-)=$ not studied.

Similar to a study of the Iranian Kermani sheep breed (Bahreini Behzadi et al., 2007), increasing differences between sexes were observed with age, which may be due to increasing endocrine differences between the sexes as the animals age.

Significant influences of birth year and shearing year on traits were also observed, which can be explained by differences in management, food availability, disease, climatic conditions (such as rate of rainfall, humidity, and temperature that affected the quality and quantity of pasture forage), and raising system differences across years. Fixed effects of birth year and shearing year have previously been studied (Bromley et al., 2000; Hanford et al., 2005; Bahreini Behzadi et al., 2007). With respect to post-weaning traits, the fixed effect of birth year was significant for BW6 and BW9 $(\mathrm{P}<0.001)$. With respect to fleece-related traits, shearing year significantly affected GFW2, GFW5, and TW\% ( $\mathrm{P}<0.001)$.

Significant effects of birth type on weight and fleece traits have previously been reported in other sheep breeds, such as Afrino (Snyman et al., 1995), Merino (Rose and Pepper, 1996), 
and Arkharmerino (Esfandyari et al., 2011). Birth type influenced traits mainly in immature animals, and significantly affected GFW1, GFW5, BW6, BW9, and BW12 (P<0.001). Age of dam was the least important environmental factor considered. However, it had a significant effect on GFW1, BW6, and BW12 $(\mathrm{P}<0.01)$ and on BW9 $(\mathrm{P}<0.05)$ and GFW4 $(\mathrm{P}<0.001)$.

\section{Heritability and variance components}

Estimates of variance components and genetic parameters for all traits are summarized in Table 3. The likelihood ratio test (LRT) was applied to choose the best model. Based on the LRT, the model with the highest log-likelihood value (alternative model) was compared with models with low log-likelihood values (null models). LRT assumes a chi-squared $\left(\chi^{2}\right)$ distribution, and its degrees of freedom are calculated by the difference between the number of parameters between the alternative model and the null models. Statistical significance for models was set at the $5.0 \%$ probability level, or $\mathrm{P} \leq 0.05$.

Table 3. Estimation of variance components and genetic parameters for fleece and post-weaning live body weight traits in Makuie sheep.

\begin{tabular}{|c|c|c|c|c|c|c|c|}
\hline Trait & MF & $\sigma_{\mathrm{a}}^{2}$ & $\sigma_{\mathrm{C}}^{2}$ & $\sigma_{e}^{2}$ & $\sigma_{\mathrm{p}}^{2}$ & $\mathrm{~h}_{\mathrm{a}}^{2}$ & $\mathrm{C}^{2}$ \\
\hline$\overline{\text { GFW1 }}$ & II & $12 \times 10^{-2}$ & $57 \times 10^{-3}$ & $98 \times 10^{-2}$ & $12 \times 10^{-1}$ & 0.10 & 0.05 \\
\hline GFW2 & II & $19 \times 10^{-1}$ & $70 \times 10^{-2}$ & $61 \times 10^{-1}$ & $87 \times 10^{-1}$ & 0.22 & 0.08 \\
\hline GFW3 & I & $46 \times 10^{-1}$ & - & 0.17 & 0.21 & 0.22 & - \\
\hline GFW4 & I & $46 \times 10^{-1}$ & - & 0.16 & 0.19 & 0.24 & - \\
\hline GFW5 & I & $47 \times 10^{-1}$ & - & 0.12 & 0.17 & 0.29 & - \\
\hline BW6 & II & 6.26 & 1.02 & 6.66 & 13.92 & 0.45 & 0.07 \\
\hline BW9 & II & 5.10 & 0.53 & 6.74 & 12.37 & 0.41 & 0.04 \\
\hline BW12 & II & 5.14 & 0.87 & 11.11 & 17.12 & 0.30 & 0.05 \\
\hline FD & I & 2.67 & - & 3.40 & 6.07 & 0.44 & - \\
\hline SL1 & I & 3.09 & - & 2.84 & 5.93 & 0.52 & - \\
\hline SL2 & I & 3.15 & - & 2.55 & 5.70 & 0.55 & - \\
\hline SL3 & I & 3.01 & - & 0.87 & 3.88 & 0.80 & - \\
\hline$\% \mathrm{TW}$ & I & 4.06 & - & 11.8 & 15.86 & 0.26 & - \\
\hline
\end{tabular}

$\mathrm{MF}=$ model fitted; $\sigma_{\mathrm{a}}^{2}=$ direct additive genetic variance; $\sigma_{\mathrm{C}}^{2}=$ variance due to permanent maternal environment; $\sigma_{\mathrm{e}}^{2}=$ error variance; $\sigma_{\mathrm{p}}^{2}=$ phenotypic variance; $\mathrm{h}_{\mathrm{a}}^{2}=$ direct heritability; $\mathrm{C}^{2}=$ heritability due to maternal permanent environment; GFW1 = greasy fleece weight at 6 months of age; GFW2 = greasy fleece weight at 16 months of age; GFW3 = greasy fleece weight at 28 months of age; GFW4 = greasy fleece weight at 40 months of age; GFW5 = greasy fleece weight at 52 months of age; BW6 = body weight at 6 months of age; BW9 = body weight at 9 months of age; BW12 = body weight at yearling age; FD = fiber diameter; SL1 = staple length (shoulder); SL2 = staple length (side); SL3 = staple length (rump); \% TW = percentage of true wool. $(-)=$ since in model I the direct additive genetic is the only source of the random variation, the maternal permanent environmental relevant parameters $(\sigma 2 \mathrm{c}$ and c2) have no value.

As in Notter and Hough (1997), Okut et al. (1999), Bromley et al. (2000), and Safari et al. (2007), direct additive genetic and maternal effects (maternal additive genetic and permanent maternal environment) were investigated in the present study. Maternal permanent environmental factors, the so-called dam-lamb association (Khan et al., 2006), including the uterus environment, amount of milk production, milk composition, and udder conditions, significantly influenced GFW1, GFW2, BW6, BW9, and BW12 $(\mathrm{P}<0.05)$. In other words, maternal random effects, especially permanent environment effects, affected pre-sexual maturation traits of animals. Makuie sheep become sexually mature at 18 months of age. As shown 
in Table 3, 4-8\% of heritabilities in the traits were due to maternal permanent environment effects. These results were in accordance with results reported by Notter and Hough (1997) and Okut et al. (1999), and were slightly lower than estimates obtained by Safari et al. (2005).

Direct heritability estimates ranged from 0.10 to 0.80 among all the traits studied. As shown in Table 3, the direct heritability was estimated to be $0.10,0.22,0.22,0.24,0.29,0.45$, 0.41 , and 0.30 for GFW1, GFW2, GFW3, GFW4, GFW5, BW6, BW9, and BW12, respectively. These traits can be considered as moderately heritable. In contrast, traits related to quality characteristics of wool could be considered as high heritability traits. The direct heritabilities for FD, SL1, SL2, SL3, and TW\% were estimated to be $0.44,0.52,0.55,0.80$, and 0.26 , respectively. This indicates that the resemblance between parent and offspring with respect to these traits is high. Estimated heritabilities for GFW2 and FD were lower than those estimated by Notter and Hough (1997). For post-weaning traits, direct heritabilities were within the range of estimates found in Kermani sheep (Bahreini Behzadi et al., 2007) and Menz sheep (Gizaw et al., 2007), and were higher than estimates of Zandi sheep (Mohammadi et al., 2010). The direct heritability estimates for staple length were higher than those calculated for Menz sheep (Gizaw et al., 2007). Considering the differences between populations, geographies, climates, management practices, and environments, such different results are not surprising.

Although a negative $r_{a m}$ value was obtained in the present study, such a negative correlation is impossible from a biological perspective (Maniatis and Pollott, 2003), but reflects the inclusion of a non-zero covariance between direct and maternal genetic effects in some models (Models IV and VI). Based on previous studies, potential reasons for obtaining a negative $r_{a m}$ value may be due to poor environmental conditions (such as udder problems, non-sufficient nutrition, and experimental conditions) (Meyer, 1992). Previous study has shown that the data structure may play a major role in producing negative correlations between direct and maternal genetic effects, since a low number of progeny records per dam in the data structure produces negative $r_{\text {am }}$ values (Maniatis and Pollott, 2003), whereas a high number of progeny records per dam produces positive $r_{\text {am }}$ values.

\section{Correlation analysis}

A bivariate analysis was used to study genetic (phenotypic) correlations. Genetic and phenotypic correlations ranged from being highly negative (-0.46) to highly positive $(0.99)$ (Tables 4 and 5). The genetic (phenotypic) correlations among post-weaning traits were higher than those of fleece-related traits. Similar to results obtained in Draa goats (Boujenane and El Hazzab, 2008), correlations (both genetic and phenotypic) were higher in adjacent traits than in non-adjacent traits. As shown in Table 4, positive correlations were consistently estimated among the same traits - weight traits and greasy fleece weight traits. Genetic (phenotypic) correlations between GFW2 and SL3, FD and SL1, FD and SL2, and FD and SL3 were estimated as $-0.18(-0.15),-0.46(0.05),-0.36(0.03)$, and $-0.27(-0.19)$, respectively. Genetic (phenotypic) correlations between GFW3 and BW6, GFW3 and BW9, and GFW3 and BW12 were estimated to be $-0.22(0.02),-0.21(0.00)$, and $0.09(0.09)$, respectively. Negative genetic (phenotypic) correlations between GFW3, GFW4, GFW5, and post-weaning growth traits revealed that heavier animals produced less wool. Estimated negative genetic correlations between fiber diameter and staple length indicated that longer fibers had finer diameters, thus fine wool breeds would be expected to produce longer staples than those of coarse wool breeds 
such Makuie sheep. These results were mostly in accordance with those of Safari and Fogarty (2003) for Merino and Leicester sheep breeds. These results indicated that genes affecting post-weaning traits had negative effects on greasy fleece weight traits. As well as genetic correlations, phenotypic variations of these two groups of traits were influenced by different sources. In other words, genes and environments influence fleece weight and post-weaning traits in different directions in the Makuie sheep breed.

Table 4. Correlations among traits related to quantity characteristics of wool.
\begin{tabular}{lcccccccc}
\hline \\
\hline GFW1 & GFW2 & GFW3 & GFW4 & GFW5 & BW6 & BW9 & BW12 \\
\hline GFW2 & - & 0.17 & 0.09 & 0.07 & 0.09 & 0.38 & 0.16 & 0.12 \\
GFW3 & 0.11 & - & 0.39 & 0.35 & 0.37 & 0.14 & 0.18 & 0.22 \\
GFW4 & 0.11 & 0.42 & - & 0.65 & 0.61 & -0.22 & -0.21 & 0.09 \\
GFW5 & 0.14 & 0.26 & 0.34 & - & 0.71 & -0.25 & -0.25 & 0.00 \\
BW6 & 0.21 & 0.19 & 0.27 & 0.37 & - & -0.36 & -0.16 & 0.10 \\
BW9 & 0.20 & 0.22 & 0.02 & 0.02 & -0.02 & - & 0.92 & 0.76 \\
BW12 & 0.13 & 0.29 & 0.00 & 0.01 & -0.02 & 0.74 & - & 0.88 \\
\hline
\end{tabular}

Upper diagonal additive genetic correlation; lower diagonal phenotypic correlation; GFW1 = greasy fleece weight at 6 months age; GFW2 = greasy fleece weight at 16 months age; GFW3 = greasy fleece weight at 28 months of age; GFW4 = greasy fleece weight at 40 months of age; GFW5 = greasy fleece weight at 52 months of age; BW6 $=$ body weight at 6 months of age; W9 = body weight at 9 months of age; BW12 = body weight at yearling age.

Table 5. Correlating among traits related to quality characteristics of wool.

\begin{tabular}{lcccccc}
\hline & GFW2 & FD & SL1 & SL2 & SL3 & \%TW \\
\hline GFW2 & & 0.46 & 0.34 & 0.24 & -0.18 & -0.27 \\
FD & 0.38 & & -0.46 & -0.36 & 0.80 & - \\
SL1 & 0.40 & 0.05 & 0.64 & & 0.74 & - \\
SL2 & 0.36 & 0.03 & 0.60 & -72 & - \\
SL3 & -0.15 & -0.19 & - & - & \\
\%TW & 0.20 & - & - & & - \\
\hline
\end{tabular}

Upper diagonal additive genetic correlation; lower diagonal phenotypic correlation; $(-)=$ due to low number of data for post-weaning and quality characteristics of fleece traits, correlation between these traits were ignored. GFW2 $=$ greasy fleece weight at 16 months age; FD = fiber diameter; SL1 = staple length (shoulder); SL2 = staple length (side); SL3 = staple length (rump); \% TW = percentage of true wool.

\section{CONCLUSIONS}

Moderate to high heritability estimates of fleece and post-weaning traits indicated good potential for genetic progress of the Makuie sheep breed by selection. High genetic correlations among post-weaning traits across different ages suggest that a selection program would be most suitable with younger animals. Highly negative correlations between fleece traits and post-weaning live body weight provide a warning of potential problems associated with selecting only one group of traits. Further studies should focus on wool characteristics, in particular wool quality characteristics, and their correlations with body weight and other traits.

\section{REFERENCES}

Abbasi MA and Ghafouri-Kesbi F (2011). Genetic and (co)variance components for body weight and body measurements in Makooei sheep. Asian-Aust. J. Anim. Sci. 24: 739-743. 
Bahreini Behzadi MR, Shahroudi FE and Van Vleck LD (2007). Estimates of genetic parameters for growth traits in Kermani sheep. J. Anim. Breed. Genet. 124: 296-301.

Boujenane I and El Hazzab A (2008). Genetic parameters for additive and maternal effects on body weights of Draa goats. Small Rumin. Res. 80: 16-21.

Bromley CM, Snowder GD and Van Vleck LD (2000). Genetic parameters among weight, prolificacy, and wool traits of Columbia, Polypay, Rambouillet, and Targhee sheep. J. Anim. Sci. 78: 846-858.

Esfandyari H, Aslaminejad AA and Rafat SA (2011). Wool characteristics in the third generation of Arkharmerino x Ghezel and Arkharmerino x Moghani crossbreed sheep. Trop. Anim. Health Prod. 43: 1337-1343.

Gizaw S, Lemma S, Komen H, Johan AM, et al. (2007). Estimates of genetic parameters and genetic trends for live weight and fleece traits in Menz sheep. Small Rumin. Res. 70: 145-153.

Hanford JK, Van Vleck LD and Snowder GD (2005). Estimation of genetic parameters and genetic change for reproduction, weight, and wool characteristics of Rambouillet sheep. Small Rumin. Res. 57: 175-186.

Jafari S, Hashemi A, Manafiazer G, Darvishzadeh R, et al. (2012). Genetic analysis of growth traits in Iranian Makuie sheep breed. Ital. J. Anim. Sci. 11: 98-102.

Khan HM, Bhat AS, Singh PK, Islam R, et al. (2006). Effect of dam lamb relationship on body weight gain of Coriedale lambs during pre weaning period. Indian J. Anim. Res. 40: 82-84.

Lang WR (1950). Non-kempy medullated fibers in Australian wool. J. Text. Inst. 41: T309-T320.

Maniatis N and Pollott GE (2003). The impact of data structure on genetic (co)variance components of early growth in sheep, estimated using an animal model with maternal effects. J. Anim. Sci. 81: 101-108.

Meyer K (1989). Restricted maximum likelihood to estimate variance components for animal models with several random effects using a derivative-free algorithm. Genet. Sel. Evol. 21:317-340.

Meyer K (1992). Variance components due to direct and maternal effects for growth traits of Australian beef cattle. Livest. Prod. Sci. 31: 179-204.

Mohammadi K, Mamouei M, Bojarpour M, Mirzadeh K, et al. (2010). Genetic parameter estimates for lamb weight at post weaning in Zandi sheep, using single-trait animal model. J. Anim. Vet. Adv. 9: 2220-2223.

Notter DR and Hough JD (1997). Genetic parameter estimates for growth and fleece characteristics in Targhee sheep. $J$. Anim. Sci. 75: 1729-1737.

Okut H, Bromley CM, Van Vleck LD and Snowder GD (1999). Genotypic expression at different ages: II. Wool traits of sheep. J. Anim. Sci. 77: 2366-2371.

Pedigree software (2000). Copyright 2000. Version 1.01. Animal Science Research Institute, Department of Animal Breeding and Genetic, Karaj.

Rose M and Pepper PM (1996). Phenotypic and genetic parameters for production traits of Merino sheep in central western Queensland. Proc. Aust. Soc. Anim. Prod. 21: 170-172.

Ryder ML and Stephenson SK (1968). Wool Growth. Academic Press, London.

Saadatnoori M and Siahmansoor S (1986). Principles of Sheep Industry. 3rd edn. Chapter 4. Armagan Publication, Iran, 101-105.

Safari A and Fogarty NM (2003). Genetic Parameters for Sheep Production Traits. Estimates from the Literature. NSW Agriculture and Australian Sheep Industry CRC, Orange.

Safari E (1986). Report for Identification of Makuie Ecotype. Chapter 1, 10-25. Published by Agriculture Ministry of Iran, Tehram.

Safari E, Fogarty NM and Gilmor AR (2005). A review of genetic parameter estimates for wool, growth, meat and reproduction traits in sheep. Livest. Prod. Sci. 92: 271-289.

Safari E, Fogarty NM, Gilmour AR, Atkins KD, et al. (2007). Genetic correlations among and between wool, growth and reproduction traits in Merino sheep. J. Anim. Breed. Genet. 124: 65-72.

SAS/STAT software (2002). User's Guide Version 9.1. SAS Institute Inc., Cary.

Snyman MA, Erasmus GJ and van Wyk JB (1995). Non-genetic factors influencing growth and fleece traits in Afrino sheep. S. Afr. Tydskr. Veck. 25: 70-74.

Snyman MA, Oliver JJ and Oliver WJ (1996). Variance components and genetic parameters for body weight and fleece traits of Merino sheep in an arid environment. S. Afr. J. Anim. Sci. 26: 11-14.

Taherpour N, Salehi M and Mirzaei F (2012). Evaluation certain environment factors on wool characteristics of Arabi sheep breeds. Open J. Anim. Sci. 2: 11-14. 